\title{
Fatigue Life Enhancement of High Reliability Metallic Components by Laser Shock Processing
}

\author{
J.L. Ocaña, J.A. Porro, M. Díaz, L. Ruiz de Lara, C. Correa, D. Peral \\ UPM Laser Centre. Univ. Politécnica de Madrid. Ctra. Valencia, km. 7.3. 28031 Madrid. Spain
}

\begin{abstract}
Laser shock processing (LSP) is increasingly applied as an effective technology for the improvement of metallic materials mechanical properties in different types of components as a means of enhancement of their mechanical behavior. As reported in the literature, a main effect resulting from the application of the LSP technique consists on the generation of relatively deep compression residual stresses field into metallic alloy pieces allowing the life improvement of the treated specimens against wear, crack growth and stress corrosion cracking. Additional results accomplished by the authors in the line of practical development of the LSP technique at an experimental level (aiming its integral assessment from an interrelated theoretical and experimental point of view) are presented in this paper. Concretely, experimental results on the residual stress profiles and associated mechanical properties modification successfully reached in typical materials under different LSP irradiation conditions are presented along with a practical correlated analysis on the protective character of the residual stress profiles obtained under different irradiation strategies. In this case, the specific behavior of a widely used material in high reliability components (especially in nuclear and biomedical applications) as AISI 316L is analyzed, the effect of possible "in-service" thermal conditions on the relaxation of the LSP effects being specifically characterized.
\end{abstract}

Keywords: Laser Shock Processing, Residual Stresses, Mechanical Behaviour, Fatigue Life Enhancement, Thermal Stability and Relaxation.

\section{INTRODUCTION}

Laser shock processing (LSP) is increasingly applied as an effective technology for the improvement of metallic materials mechanical properties in different types of components as a means of enhancement of their corrosion and fatigue life behavior. Specially wear resistance, stress corrosion cracking susceptibility and crack propagation rate seem to be material properties specially improved by LSP treatments [1-4].

Although the technique was initially developed for the improvement of the fatigue cracking resistance of materials used in the aeronautic applications (specifically Aluminum alloys), Titanium alloys and different types of stainless steels are being extensively investigated in the frame of different areas of application, especially the aerospatial sector itself but also in the nuclear, automotive and biomedical sectors on the basis of the commercial availability of new powerful laser sources able to provide intensities exceeding the GW/ $\mathrm{cm}^{2}$ level [5-10].

In this paper, the special case of stainless steels and, more particularly, AISI 316L, is considered in view of the important number of applications of this material both in the energy sector (derived from its excellent corrosion resistant properties compatible with very convenient hot deformation (creep) resistance and good electron beam and laser weldability [1112]) and its very promising applicability in the biomedical sector as structural material for external implants, combining excellent corrosion resistance, convenient surface deformability and good biocompatibility properties [13-14].

The proposed investigation on the effect of thermal treatments on the residual stresses fields induced by LSP is motivated because in some industrial applications, as i.e. in the case of nuclear power plants, materials are subject to repeated thermal stresses as a result of thermal gradients occurring during heating/cooling cycles (either in start-up/shutdown or in transient routine operations) close or directly in the creep range, what finally leads to an effective working life reduction due to creep-fatigue interaction regimes.

The study is considered to be relevant as the beneficial effects derived from induction of near-surface work-hardened nanoscale microstructures by different thermo-mechanical treatments such as LSP can prevail and result in an effective improvement of components fatigue life if the induced residual stresses fields remain stable during in-service mechanical

Copyright 2015 Society of Photo-Optical Instrumentation Engineers (SPIE). One print or electronic copy may be made for personal use only. Systematic reproduction and distr bution, duplication of any material in this paper for a fee or for commercial purposes, or modification of the content of the paper are prohibited. 
loading and/or exposme to high temperatmes and LSP has been identified as one of the treatments providing a higher degree of stability of these fields [15].

Although the problem of high-temperature fatigue behaviom and residual stress stability of laser shock processed stainless steels has been previously considered by other authors [16-17], a detailed analysis is required in order to cotTelate (1) the capability of the LSP treatment at different processing intensities to induce residual stresses fields into the treated material, (2) the thermal stability of these residual stresses fields depending on the generated microstmctures and (3) the fmal fatigue life enhancement achieved in critica!components after the thennal release motivated by high temperature working cycles (which is expected not to be complete according to the specific kind of material dislocations and cold work produced by the treatment). Additionally, the specific case of AISI 316L steel is considered to deserve a specific study in this sense in view of the referred important range of applications in which it is used as structural material.

From a concrete point of view, the effect of the application of different typical LSP intensities on the residual stresses fields introduced in this material, the thermal stability of these residual stresses and the fmal results in tenns of fatigue life extension on standard specimens will be ana.lyzed.

\section{EXPERIMENTAL SETUP AND MATERIALS}

The practica!development of LSP processes has been successfully implemented at the authors Centre. The practica! inadiation system used for the experiments reported in this paper is essentially the same repmted in previous contributions by the authors (see, i.e. [18-19]) and is schematically and photographically shown in Fig. I. Using pmified water as confining medium, the test piece is fixed on a holder and is driven by means of a. robotized ann needed for the inadiation of extended areas of material following a pre-defmed pulse ovedapping strategy.

The laser beam (Q-switch Nd:YAG, $2.8 \mathrm{~J} /$ pulse, 9.4 ns FWHM pulse length, 10Hz repetition rate) is conducted to the interaction area (typically circular spot $1.5 \mathrm{~mm}$ diameter) without any protective coating by means of a reflecting mirror and a focusing lens. The control of the pmity of the confming medium is impmtant in order to avoid the fonnation of water bubbles or increasing concentra.tion of impmities resulting frommaterial ablation following the laser inadiation.
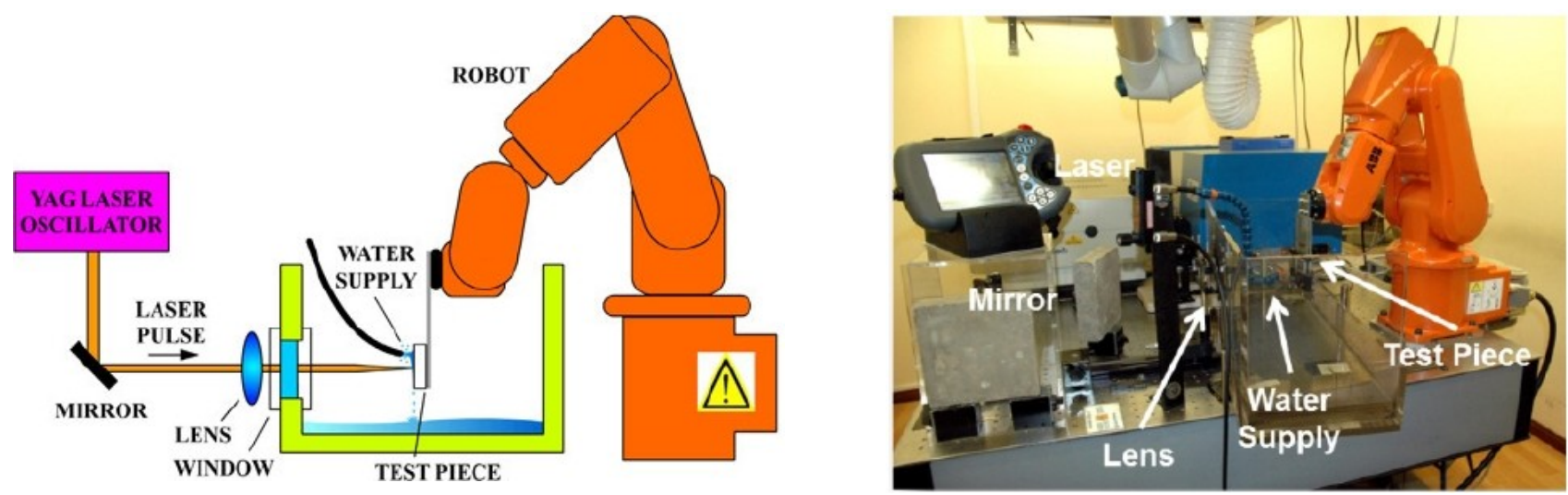

Figure 1: $\quad$ Schematic representation and photographic view of the LSP in·adiation setup used in the rep01ted experiments.

The LSP experiments reported in this paper were perfmmed on AISI 316L steel with composition shown in Table 1. The as-received material, in the fmm of $6 \mathrm{~mm}$ thick plates, had been hot rolled and solution annealed betv:een $1050^{\circ} \mathrm{C}$ and $1100^{\circ} \mathrm{C}$. The initial mechanical properties of the trea.ted material were experimentally detetmined using dog-bone type specimens according to ASTM E 8M standard [20] and presented in Table 2.

Table 1: Percent Composition of AISI 316L Steel Used in the Rep01ted Experiments

\begin{tabular}{|c|c|c|c|c|c|c|c|c|c|c|}
\hline Element & $\mathbf{C}$ & $\mathbf{C r}$ & $\mathbf{N i}$ & $\mathbf{M o}$ & $\mathbf{M n}$ & $\mathbf{S i}$ & $\mathbf{N}$ & $\mathbf{P}$ & $\mathbf{S}$ & $\mathbf{F e}$ \\
\hline \% wt & 0.018 & 16.815 & 10.086 & 2.044 & 1.294 & 0.458 & 0.047 & 0.032 & 0.003 & Bal. \\
\hline
\end{tabular}

Copyright 2015 Society of Photo-Optical Instrumentation Engineers (SPIE). One print or electronic copy may be made for personal use only. Systematic reproduction and distr bution, duplication of any material in this paper for a fee or for commercial purposes, or modification of the content of the paper are prohibited. 
Table 2: Initial Mechanical Properties of AISI 316L Steel Used in the Rep01ted Experiments

\begin{tabular}{|c|c|}
\hline Property & Value \\
\hline Elastic Modulus [GPa] & 177.2 \\
\hline Offset Tensile Yield Strength [MPa] & 355.4 \\
\hline Ultimate Tensile Strength [MPa] & 633.6 \\
\hline
\end{tabular}

The irradiation geometry used for the investiga.tions is displa.yed in Figure 2 together with a photogra.ph of the resulting aspect of the work piece a fter the a.pplica.tion of the LSP trea.tment and subsequent residual stresses field detennination by the hole drilling method (ASTM E837 Standard [21]).
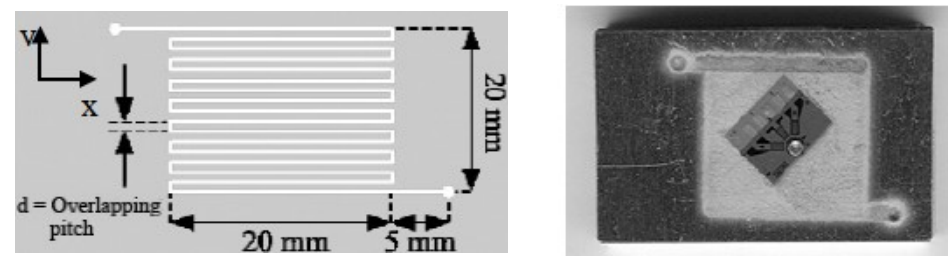

Figure 2. Schematic representation of the LSP surface sweeping strategy and photograph showing a real test piece after processing.

Besides la.ser pulse energy and interaction diameter, the ma.in varying experimental parameters are the so-ca.lled "overlapping pitch", d, a direct measure of the distance between both adjacent laser shots and paral1e1 processing tracks and the laser beam spot diameter, 4>, detennining the fma.1 energy density a.pplied by ea.ch la.ser pulse on the treated material. Altogether, both parameters detennine the operational parameters EOD (Equivalent Overlapping Density), EED (Equivalent Energy Density) and ELOF (Equivalent Local Overlapping Factor), all precisely defined in a previous reference by the authors [18].

For the analysis of the stability of the residual stresses fie1ds induced by LSP, 40 nun x 40 mm samp1es were one-side treated according to the experimental variable overlapping procedure original1y defined by the authors [18-19]. For the rep01ted analysis, tv ro equally $\mathrm{x}$-y spaced overlapping schemes were se1ected imp1ying respective equiva1ent overlapping densities (EOD's) of900 and 1600 pulses $/ \mathrm{cm}^{2}$ (respective overlapping pitches of $\mathrm{d}=0.33 \mathrm{~mm}$ and $\mathrm{d}=0.25$ nun).

For the analysis of the fatigue 1ife enhancement induced by the LSP treatment, both in pristine and thennally aged forrns, standard dog-bone type specimens used for fatigue test were ma.chined in accordance with ASTM standard E466 [22], with 150 nun 1ength. For these specimens, the LSP treatment was applied on both sides over approximate areas of 35 $\mathrm{mm}$ x $20 \mathrm{~mm}$ in their centra1reduced zone following a sweeping stra.tegy progressing along the transverse dimension.

\section{EXPERIMENTAL RESULTS}

For the proposed analysis, both types of samples were LSP treated according to the tv ro refened parametric conditions and subject to thennal aging in order to eva1uate the RS's fields stability and the resulting performance under fatigue life tests. According to the practical working conditions of a great proportion of AISI 316L components, a thennal aging temperature of $500^{\circ} \mathrm{C}$ maintained over 8 hours (considered as sufficient for pure thennal stresses release) was se1ected as testing reference. No experimentation beyond this tempera.ture was made in view of the well know drop in tensile stress and creep onset starting at about $550^{\circ} \mathrm{C}$ for the considered material [11-12].

Figure 3 shows tvro of the considered specirnens trea.ted at EOD $=900$ pulses $/ \mathrm{cm}^{2}$ prior to and after app1ication of thennal aging.
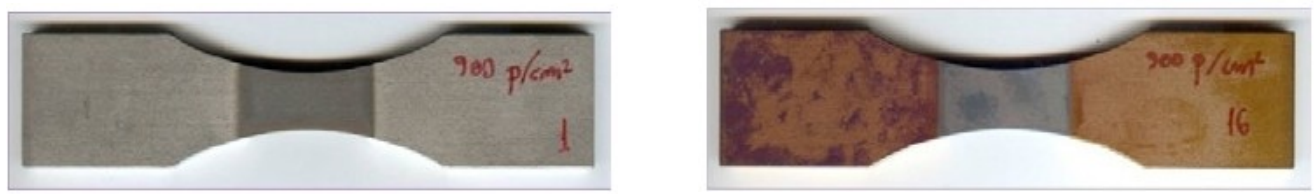

Figme 3. LSP treated specimens at EOD $=900$ pulses $/ \mathrm{cm}^{2}$ without and with thermal aging at $\mathrm{S} 00^{\bullet} \mathrm{C}$ during 8 hours. 


\subsection{Residual Stresses Fields}

Residual stress distributions reached in the LSP treated specimens were determined according to the ASTM E837-01 Standard Test Method for Determining Residual Stresses by the Hole Drilling Strain Gage Method [21]. Strain gage rosettes CEA-13-062UM-120 along with a Vishay Measurements $®$ RS-200 milling guide were used.

Fig. 4 shows the in-depth profiles obtained for LSP-induced Mohr maximum (i.e. minimum in absolute value) RS's with the two considered LSP treatment conditions before and after application of thermal aging.
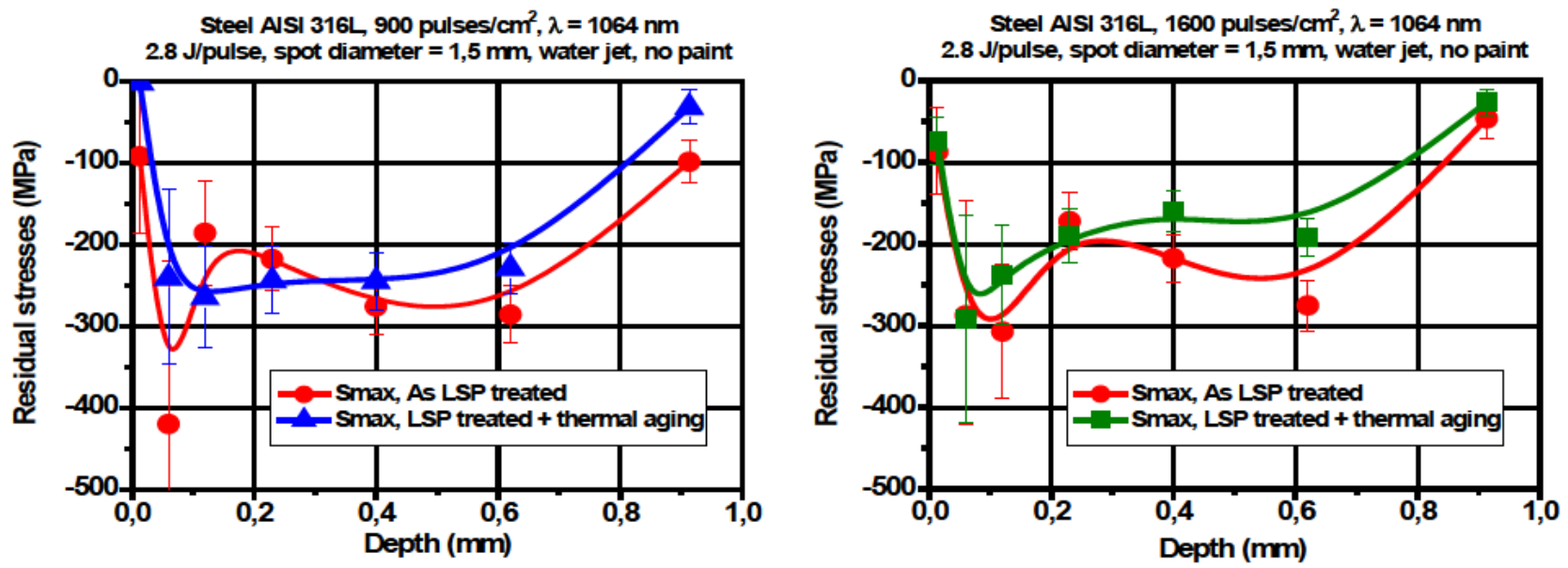

Figure 4. In-depth profiles obtained for LSP-induced Mohr maximum (i.e. minimum in absolute value) RS's with LSP treatment at $\mathrm{EOD}=900$ pulses $/ \mathrm{cm}^{2}$ (left) and EOD $=1600$ pulses $/ \mathrm{cm}^{2}$ (right) before and after application of thermal aging at $500^{\circ} \mathrm{C}$ during 8 hours.

The effect of the applied heat treatments can be clearly observed in both cases as both a decrease of the maximum compressive residual stress achieved in the treated material and a general softening of the level of compressive residual stresses available in the material depth explored by the RS's determination method. Both facts imply in practice a certain degree of compressive RS's relaxation that, undoubtedly, must have a certain effect on the material fatigue life, but it is also noticeable that the RS's release is by no means complete, what can be attributed to the special kind of thermally irreversible dislocations induced by the LSP treatment as anticipated in ref. [15].

Additionally, in the case of EOD $=1600$ pulses $/ \mathrm{cm}^{2}$ (a LSP treatment intensity considered as a certain threshold for AISI $316 \mathrm{~L}$ in order to produce RS's fields deep enough to provide an effective protection against crack propagation), the effect of the applied thermal cycle is not enough to relax completely the minimum value of compressive residual stress induced by the treatment at the material surface maintaining at the same time a reasonable level of compressive values through the material depth close to the surface (up to $1 \mathrm{~mm}$ according to the determination method), a result that allows to anticipate a certain improved behaviour of the specimens treated under this condition in fatigue life tests.

\subsection{Fatigue life}

Fatigue tests of LSP treated specimens according to the two specified treatment conditions both prior and after thermal aging were conducted in order to evaluate the degree of permanence of the protective effect of the LSP treatments under such relaxation process. The corresponding tests were carried out on a MTS 810 servo-hydraulic system at room temperature in air. The loading axis was parallel to the rolling direction of the samples and the test was performed in load-control. To ensure a precise alignment of the specimen gripping fixtures, an alignment module supplied for MTS controlled with a specific alignment system software was used in order to allow a highly accurate loading of the specimen along its longitudinal axis with minimal bending strain. The fatigue results were presented using the classic S$\mathrm{N}$ fatigue curve format with stress amplitude, Sa, plotted as a function of cycles to failure, $\mathrm{N}$, establishing as fatigue limit the loading for which the material reaches $10^{6}$ cycles without failure. The testing was limited to tension-tension loading with mean stress conditions described by $\mathrm{R}=0.1$ and a sinusoidal waveform of $10 \mathrm{~Hz}$. 
In figure 5, the referred S-N curves corresponding to the two specified LSP treatment conditions are presented compared to the reference of the pristine AISI $316 \mathrm{~L}$ material in the same experimental testing conditions, both after pure LSP treatment and after LSP treatment followed by thermal aging in the specified conditions.
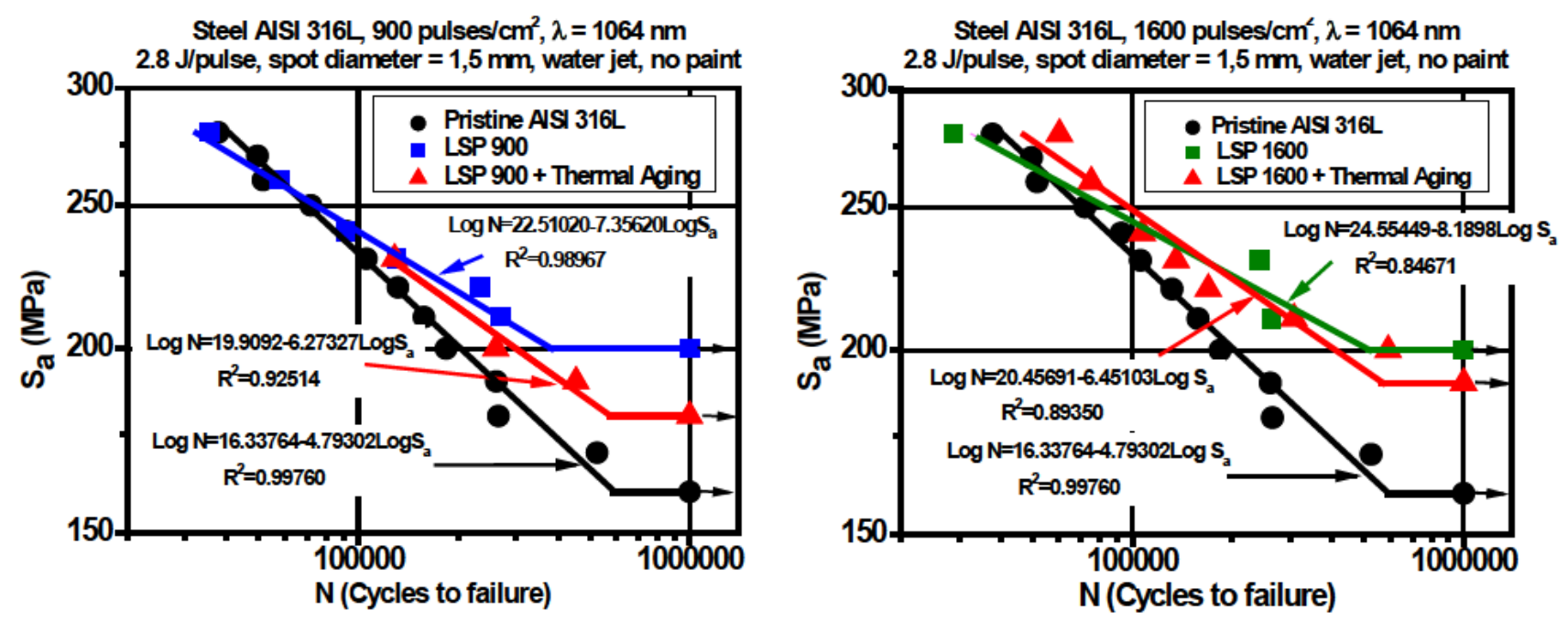

Figure 5. S-N curves corresponding to comparison to pristine AISI 316L material of LSP treated specimens and LSP treated specimens subject to ulterior thermal aging at $500^{\circ} \mathrm{C}$ during 8 hours. Left: Results for EOD $=900$ pulses $/ \mathrm{cm}^{2}$. Right: Results for $\mathrm{EOD}=1600 \mathrm{pulses} / \mathrm{cm}^{2}$.

In both curves, the improvement of fatigue life provided by the LSP treatment at both EOD's can be clearly observed (rise in runout amplitude from about $160 \mathrm{MPa}$ to about $200 \mathrm{MPa}$ in both cases) but, additionally and most important for the prospects of the present work, a maintenance of the protective effect provided by the LSP treatments after the application of the considered thermal aging cycle can be clearly observed also in both cases.

Within the limitations due to statistical factors in the performed tests, even in the case of EOD $=900 \mathrm{pulses} / \mathrm{cm}^{2}$, an increase of about $12.5 \%$ (from 160 to $180 \mathrm{MPa}$ in runout amplitude over the pristine AISI $316 \mathrm{~L}$ ) is still observed to be maintained after thermal aging and the increment is even higher (increase of about $18.75 \%$ in runout amplitude over the pristine material face to the $25 \%$ obtained without thermal aging), in the case of EOD $=1600$ pulses $/ \mathrm{cm}^{2}$ treatment (in a consistent way with the observed better maintenance of the compressive RS's fields reported in the previous section).

\section{DISCUSSION}

In view of the frequent need to protect high reliability metallic components in thermally aggressive environments, the capability of the LSP treatment to maintain its demonstrated protective character against fatigue failure in service conditions of thermal aging has been analyzed. In view of its important domain of applications in the energy and biomedical sectors, the behavior of the AISI 316L stainless steel has been studied as a representative sample material.

Experimental determination of residual stresses fields in the LSP treated materials prior and after to the application of characteristic thermal aging cycles has confirmed an important degree of maintenance of such fields presumably due to the specific character of the predominantly irreversible mechanical dislocations induced by the LSP treatment and as indicated by several authors in the literature. Of course, the effect is much more evident for LSP treatment intensities above a certain treatment intensity threshold implying the generation of such type of dislocations.

In full consistency with this fact, the improvement of fatigue life of standard test specimens treated by LSP has been observed (within the limits of the statistical uncertainties associated to testing procedures, but with a clear tendency) to remain to an appreciable degree after the application of a characteristic thermal aging cycle.

Consequently, and although needing further study for a more precise evaluation of the practical working limits for inservice reliable performance of components of the analyzed material, the clear conclusion can be extracted of the suitability of the LSP technique for the practical improvement of the fatigue life of high reliability components in AISI 
316L (in a similar way to the case of other characteristic materials previously studied by the authors [18-19]) even in conditions implying service temperatures in the range of at least $500^{\circ} \mathrm{C}$.

Provided that the large variety of mechanical and structural components suitable for surface properties and resistance enhancement by means of LSP in different strategic sectors (aeronautic, automotive, nuclear, heavy chemical equipment, etc.), the technique is being widely recognized as true breakthrough in the field of thermo-mechanical surface treatments, so that the research efforts conducted in an important number of laboratories and R\&D departments of leading companies are rapidly increasing. Additionally, concerning the practical significance of the LSP technique, it is considered that the life cycle improvement achievable by the application of the treatment to specific high reliability components in these sectors has an evident positive incidence on their long-term ecological balance, so that the technique has to be considered as a highly sustainability-supporting one.

\section{ACKNOWLEDGEMENTS}

Work partly supported by MICINN/MINECO (Spain; Projects MAT2008-02704/MAT and MAT2012-37782) and EADS-CASA (Spain).

\section{REFERENCES}

[1] Y. Sano et al.: “Underwater Laser Processing to Improve Residual Stress on Metal Surface”. In: Proceedings of the 6th International Welding Symposium of Japan Welding Society, Nagoya, Japan, 501-506 (1996).

[2] C. Rubio-González et al.: Mat. Sci. Eng. A, 386, 291-295 (2004).

[3] J.L. Ocaña et al.: "Laser Shock Processing as a Method for Surface Properties Modification of Metallic Materials”. In: Shot Peening and other Mechanical Surface Treatments. V. Schulze, A. Niku-Lari, Eds. I.I.T.T. Paris, 466-471 (2005).

[4] U. Sánchez-Santana et al.: Wear, 260, 847-854 (2006).

[5] C.S. Montross et al.: Int. J. of Fatigue, 24, 1021-1036 (2002).

[6] M. Rozmus-Górnikowska: Acta Physica Polonica A, 117, 808-811 (2010).

[7] S.R. Mannava et al.: Int. J. Struct. Integ. 2, 101-113 (2011).

[8] Y. Sano et al.: Nucl. Inst. Meth. Phys. Res. B, 121, 432-436 (1997).

[9] C. Rubio-González et al.: Mat. Sci. Eng. A, 528, 914-919 (2011).

[10] K.Y. Luo et al.: Mat. Sci. Eng. A, 528, 4783-4788 (2011).

[11] S.C. Tjong et al.: J. Nucl. Mat., 227, 24-31 (1995).

[12] S.G. Chowdhury et al.: Acta Materialia, 53, 3951-3959 (2005).

[13] K.H. Lo et al.: Mat. Sci. Eng. R, 65, 39-104 (2009).

[14] Suyitno et al.: Int. J. Min., Metall. \& Mat., 19, 1093-1099 (2012).

[15] P.S. Prevéy: "The Effect of Cold Work on the Thermal Stability of Residual Compression in Surface Enhanced In718”. Proc. 20th ASM Materials Solutions Conference \& Exposition. St. Louis (Missouri, USA), October 1012, (2000).

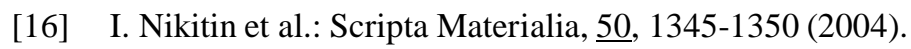

[17] I. Nikitin, I. Altenberg: Mat. Sci. Eng. A, 465, 176-182 (2007).

[18] J.L. Ocaña et al.: Materials Science Forum, $\underline{638}-\underline{642}, 2446-2451$ (2010).

[19] J.L. Ocaña et al.: Materials Science Forum, 706-709, 2565-2570 (2012).

[20] ASTM International: "E8/E8M: Standard Test Methods for Tension Testing of Metallic Materials”. v. 09 (2010).

[21] ASTM International: "E837-08 Standard Test Method for Determining Residual Stresses by the Hole-Drilling Strain Gage Method”. v. 04 (2008)

[22] ASTM International: "E466-07 Standard Practice for Conducting Force Controlled Constant Amplitude Axial Fatigue Tests of Metallic Materials”. V. 96.e1 (2002) 